\title{
BMJ Open Improved risk stratification of patients with atrial fibrillation: an integrated GARFIELD-AF tool for the prediction of mortality, stroke and bleed in patients with and without anticoagulation
}

Keith A A Fox, ${ }^{1}$ Joseph E Lucas, ${ }^{2}$ Karen S Pieper, ${ }^{3}$ Jean-Pierre Bassand,,${ }^{4,5}$ A John Camm, ${ }^{6}$ David A Fitzmaurice, ${ }^{7}$ Samuel Z Goldhaber, ${ }^{8}$ Shinya Goto, ${ }^{9}$ Sylvia Haas, ${ }^{10}$ Werner Hacke, ${ }^{11}$ Gloria Kayani, ${ }^{5}$ Ali Oto, ${ }^{12}$ Lorenzo G Mantovani, ${ }^{13}$ Frank Misselwitz, ${ }^{14}$ Jonathan P Piccini, ${ }^{3}$ Alexander G G Turpie, ${ }^{15}$ Freek W A Verheugt, ${ }^{16,17}$ Ajay K Kakkar, ${ }^{5,18}$ for the GARFIELD-AF Investigators

To cite: Fox KAA, Lucas JE, Pieper KS, et al. Improved risk stratification of patients with atrial fibrillation: an integrated GARFIELD-AF tool for the prediction of mortality, stroke and bleed in patients with and without anticoagulation. BMJ Open 2017;7:e017157. doi:10.1136/ bmjopen-2017-017157

- Prepublication history and additional material for this paper are available online. To view these files, please visit the journal online (http://dx.doi. org/10.1136/bmjopen-2017017157).

Received 4 April 2017 Revised 21 August 2017 Accepted 25 August 2017

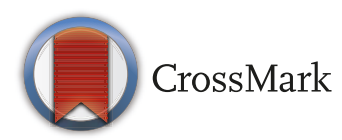

For numbered affiliations see end of article.

Correspondence to Professor Keith A A Fox; k.a.a.fox@ed.ac.uk

\section{ABSTRACT}

Objectives To provide an accurate, web-based tool for stratifying patients with atrial fibrillation to facilitate decisions on the potential benefits/risks of anticoagulation, based on mortality, stroke and bleeding risks.

Design The new tool was developed, using stepwise regression, for all and then applied to lower risk patients. C-statistics were compared with $\mathrm{CHA}_{2} \mathrm{DS}_{2}$-VASc using 30 -fold cross-validation to control for overfitting. External validation was undertaken in an independent dataset, Outcome Registry for Better Informed Treatment of Atrial Fibrillation (ORBIT-AF).

Participants Data from 39898 patients enrolled in the prospective GARFIELD-AF registry provided the basis for deriving and validating an integrated risk tool to predict stroke risk, mortality and bleeding risk.

Results The discriminatory value of the GARFIELD-AF risk model was superior to $\mathrm{CHA}_{2} \mathrm{DS}_{2}$-VASc for patients with or without anticoagulation. C-statistics $(95 \% \mathrm{Cl})$ for all-cause mortality, ischaemic stroke/systemic embolism and haemorrhagic stroke/major bleeding (treated patients) were: 0.77 (0.76 to 0.78$), 0.69$ (0.67 to 0.71 ) and 0.66 (0.62 to 0.69 ), respectively, for the GARFIELD$\mathrm{AF}$ risk models, and 0.66 (0.64-0.67), 0.64 (0.61-0.66) and 0.64 (0.61-0.68), respectively, for $\mathrm{CHA}_{2} \mathrm{DS}_{2}$-VASc (or HAS-BLED for bleeding). In very low to low risk patients (CHA $\mathrm{DS}_{2}$-VASc 0 or 1 (men) and 1 or 2 (women)), the $\mathrm{CHA}_{2} \mathrm{DS}_{2}$-VASc and HAS-BLED (for bleeding) scores offered weak discriminatory value for mortality, stroke/ systemic embolism and major bleeding. C-statistics for the GARFIELD-AF risk tool were 0.69 (0.64 to 0.75 ), 0.65 ( 0.56 to 0.73 ) and 0.60 (0.47 to 0.73 ) for each end point, respectively, versus 0.50 (0.45 to 0.55$), 0.59$ (0.50 to 0.67 ) and 0.55 (0.53 to 0.56 ) for $\mathrm{CHA}_{2} \mathrm{DS}_{2}$-VASc (or HAS-BLED for bleeding). Upon validation in the ORBIT-AF population, C-statistics showed that the GARFIELD-AF risk tool was effective for predicting 1-year all-cause mortality using the full and simplified model for all-cause mortality: C-statistics 0.75 ( 0.73 to 0.77 ) and 0.75 (0.73 to 0.77 ), respectively, and for predicting for any stroke or systemic embolism over 1 year, C-statistics 0.68 (0.62 to 0.74).

Conclusions Performance of the GARFIELD-AF risk tool was superior to $\mathrm{CHA}_{2} \mathrm{DS}_{2}-\mathrm{VASc}$ in predicting stroke and mortality and superior to HAS-BLED for bleeding, overall and in lower risk patients. The GARFIELD-AF tool has the potential for incorporation in routine electronic systems, and for the first time, permits simultaneous evaluation of ischaemic stroke, mortality and bleeding risks.

Clinical Trial Registration URL: http://www.clinicaltrials. gov. Unique identifier for GARFIELD-AF (NCT01090362) and for ORBIT-AF (NCT01165710).

\section{INTRODUCTION}

Guidelines recommend the use of oral anticoagulants (OACs), either oral vitamin K antagonists (VKAs, eg, warfarin) or non-VKA oral anticoagulants (NOACs), for stroke prevention in patients with atrial fibrillation (AF) and a risk of stroke. ${ }^{1-3}$ Anticoagulation is recommended by guidelines in patients with at least one risk factor for stroke, as defined by $\mathrm{CHA}_{2} \mathrm{DS}_{2}$-VASc (Congestive heart failure $(\mathrm{CHF}) /$ left ventricular dysfunction, Hypertension, Age $\geq 75$ (doubled), Diabetes, Stroke (doubled) - Vascular disease, Age 65-74 and Sex category (female)). ${ }^{14}$ Although the relationship between increasing $\mathrm{CHA}_{2} \mathrm{DS}_{2}$-VASc risk score values and stroke risk is well defined, there remains clinically important uncertainty in defining the population at truly low risk of stroke. Among such patients, the benefits of OACs may not exceed the risks of bleeding. ${ }^{3}$ In the derivation of the $\mathrm{CHADS}_{2}$ and $\mathrm{CHA}_{2} \mathrm{DS}_{2}-$ VASc risk scores, relatively few very low to low risk patients were included in these analyses (eg, in the derivation of $\mathrm{CHA}_{2} \mathrm{DS}_{2}$-VASc, 103 
patients had a score of 0 , and 162 patients a score of 1 out of 1084 patients evaluated by Lip and colleagues, 2010). ${ }^{45}$

Large-scale international registry programmes demonstrate substantial divergence in clinical practice compared with guideline recommendations. ${ }^{6}$ For example, the Global Anticoagulant Registry in the FIELD-Atrial Fibrillation (GARFIELD-AF) registry observed that between 46\% (2010-2011) and 59\% (2014-2015) of patients with a $\mathrm{CHA}_{2} \mathrm{DS}_{2}$-VASc score of 0 or 1 were anticoagulated. ${ }^{7}$ In part, this clinical uncertainty reflects the poor predictive value of $\mathrm{CHA}_{2} \mathrm{DS}_{2}-\mathrm{VASc}$, especially in very low to low stroke risk patients $\left(\mathrm{CHA}_{2} \mathrm{DS}_{2}\right.$-VASc score of 0 or 1 (men) and 1 or 2 (women)). It may also reflect other factors such as the introduction of NOACs, for example, with the increasing use of this new class of treatment for patients at all levels of stroke risk, including those patients with a very low stroke risk $\left(\mathrm{CHA}_{2} \mathrm{DS}_{2}\right.$-VASc score of 0$){ }^{7}$ Thus, clinicians are basing their decision to anticoagulate on factors beyond those employed in conventional scores of stroke risk. Unless the risks of ischaemic stroke and major bleeding are accurately characterised for such patients using contemporary databases, it is not possible to weigh the potential benefits of anticoagulation against the hazards of bleeding. For this reason, we have developed an integrated risk tool that allows simultaneous calculation of not only ischaemic stroke risk but also and major bleeding risk and all-cause mortality to help facilitate greater guideline adherence.

In this report, we compare the predictive value of this new integrated risk assessment tool with the $\mathrm{CHA}_{2} \mathrm{DS}_{2}$ VASc risk tool for the overall population, and then in very low to low risk patients $\left(\mathrm{CHA}_{2} \mathrm{DS}_{2}-\mathrm{VASc}\right.$ score of 0 or 1 (men) and 1 or 2 (women)), that is, in those patients in whom OAC is not recommended by the ESC. The 2016 European Society of Cardiology (ESC) Guidelines recommend OAC therapy only in patients with at least two risk factors for stroke, that is, $\mathrm{CHA}_{2} \mathrm{DS}_{2}$-VASc risk score of 2 or more in men and 3 or more in women. ${ }^{6}$ As a sensitivity analysis, we also evaluated those with a $\mathrm{CHA}_{2} \mathrm{DS}_{2}$-VASc score of 0,1 and 2 (men) and 1, 2 and 3 (women).

\section{MATERIALS AND METHODS Design}

The new risk stratification tool was derived from prospective data gathered between March 2010 and July 2015 from the GARFIELD-AF registry, undertaken in 35 countries in adults with recently diagnosed $\mathrm{AF}^{8}$ Models were trained on indicators for three events (all-cause mortality, ischaemic stroke/systemic embolism (SE) and any major bleed) that occurred within 1 year of enrolment. The derivation of the GARFIELD-AF risk models used similar statistical methods as for the GRACE model for risk stratifying patients with acute coronary syndrome (ACS) ${ }^{9}$ with C-statistics estimated from regression models. ${ }^{10}$ Analogous to other bleeding models, only patients from GARFIELD-AF on OACs were used in developing the model for major bleeding.
Comparisons of the performance of the new GARFIELD-AF risk models were made with (A) $\mathrm{CHA}_{2} \mathrm{DS}_{2}-$ VASc score (for all-cause mortality and ischaemic stroke/ $\mathrm{SE}$ ) and (B) HAS-BLED score for major bleeding. The performance of the new risk schemas was tested in the whole GARFIELD-AF population as well as in patients treated and untreated with OACs for stroke prevention at baseline, and so permitting a better comparison with $\mathrm{CHA}_{2} \mathrm{DS}_{2}$-VASc.

We also tested our hypothesis that the performance of the GARFIELD-AF risk model would be better than the $\mathrm{CHA}_{2} \mathrm{DS}_{2}$-VASc score in discriminating between patients with a lower stroke risk. To be consistent with the 2016 ESC Guidelines, we considered a $\mathrm{CHA}_{2} \mathrm{DS}_{2}$-VASc score of 0 or 1 (men) and 1 or 2 (women) as representative of very low to low stroke risk. ${ }^{6}$ As a sensitivity analysis, we also evaluated those with a $\mathrm{CHA}_{2} \mathrm{DS}_{2}$-VASc score of 0-2 (men) and 1-3 (women).

Subsequently, a simplified risk tool for all-cause mortality was derived to facilitate wider potential application of the GARFIELD-AF risk model in electronic systems. The model for ischaemic stroke/SE contained sufficiently few factors to be potentially used as a web-based tool without simplification, that is, world region, age, race, history of stroke, history of bleeding, heart failure, renal disease and use of OAC. Similarly, the full model for major bleeding, based on a subset of 25677 patients who were on OACs, was also developed as a web tool using: age, vascular disease and kidney disease.

The validity of the GARFIELD-AF risk models for all end points and the simplified GARFIELD-AF model for all-cause mortality was tested externally in patients with AF from an entirely independent US-based registry-the Outcome Registry for Better Informed Treatment of Atrial Fibrillation (ORBIT-AF) registry. ${ }^{11-14}$ As part of the validation, the GARFIELD-AF model was also compared with the Anticoagulation and Risk factors in Atrial Fibrillation (ATRIA) score in predicting major bleed in patients on OAC treatment.

\section{Registry population}

The analysis was conducted in 39898 patients enrolled in GARFILED-AF between March 2010 and July 2015 (cohort 1: March 2010-October 2011; cohort 2: August 2011-June 2013; cohort 3: April 2013-October 2014 and cohort 4: March 2014-July 2015). The data were extracted from the study database on 28 July 2016. To minimise recruitment bias in GARFIELD-AF, investigator sites were selected randomly from representative care settings in each participating country (apart from 18 sites, out of $>1000$ ) and consecutive patients were enrolled, regardless of whether or not they received antithrombotic treatment. Eligible patients comprised adults (aged $\geq 18$ years) who had been diagnosed with $\mathrm{AF}$ (not related to mechanical valves or severe valve disease, ie, non-valvular) within the previous 6 weeks and had at least one risk factor for stroke as judged by the investigator (a complete list of investigators is given in 
the online supplementary file). These risk factors were not prespecified in the protocol, nor were they limited to the components of risk stratification schemes, such as $\mathrm{CHA}_{2} \mathrm{DS}_{2}$-VASc. Patients with a transient reversible cause of $\mathrm{AF}$ and those for whom follow-up was not envisaged or possible were excluded.

\section{Study procedures and outcome measures}

The methods employed in GARFIELD-AF have been published. ${ }^{1516}$ In brief, baseline characteristics included: patient characteristics, medical history, care settings, type of $\mathrm{AF}$, date and method of diagnosis, symptoms of AF, type of anticoagulant treatment (VKAs, factor Xa inhibitors and direct thrombin inhibitors, as well as antiplatelet treatment $(\mathrm{AP})){ }^{8}$

Data on components of the $\mathrm{CHA}_{2} \mathrm{DS}_{2}-\mathrm{VASc}^{17}$ and HAS-BLED ${ }^{18}$ risk stratification schemes were also collected to assess the risks of ischaemic stroke and major bleeding. Collection of follow-up data occurred at 4-monthly intervals based on telephone interviews and hospital records up to 24 months. The incidence of ischaemic stroke, transient ischaemic attack (TIA), SE, ACS, hospitalisation, death (cardiovascular and non-cardiovascular), CHF (occurrence or worsening) and bleeding (severity and location) was documented. An audit and quality control programme was applied, ${ }^{19}$ and data were examined for completeness and accuracy by the coordinating centre (TRI, London, UK). By design, 20\% of all electronic case report forms in the GARFIELD-AF registry were monitored against source documentation at sites over the 8 years of recruitment and follow-up. ${ }^{19}$

\section{Definitions of end points and analytical methods}

Major bleed was classified by investigators according to the International Society on Thrombosis and Haemostasis definition. Stroke/SE were defined as the combined end points of: ischaemic stroke, SE and TIA. Major bleeds, including intracranial bleeds, were defined as a combined end point of: haemorrhagic stroke and any major bleed.

Vascular disease included patients with peripheral artery disease and/or coronary artery disease (CAD) with or without a history of ACS. Hypertension was defined as a documented history of hypertension or blood pressure $>140 / 90 \mathrm{~mm} \mathrm{Hg}$. Chronic kidney disease (CKD) was classified by investigators according to the National Kidney Foundation Kidney Disease Outcomes Quality Initiative guidelines into two groups ${ }^{20}$ : moderate-to-severe, or mild or none. CHF was defined as a history (cohorts 1 and 2) or current or prior history of CHF (cohorts 3 and 4).

The $\mathrm{CHA}_{2} \mathrm{DS}_{2}$-VASc score was the sum of points after addition of one point each for CHF, hypertension, diabetes, vascular disease, age 65-74 years and female gender, and two points each for age $\geq 75$ years and previous SE. This score ranged from 0 to $9 .{ }^{17}$ The HAS-BLED score was the sum of points after addition of one point each for hypertension, abnormal renal/liver function, stroke, bleeding history or predisposition, labile international normalised ratios, elderly ( $>65$ years) and drugs/alcohol concomitantly $^{18}$ (fluctuations in international normalised ratios were not included).

\section{Statistical modelling}

Four methods of model generation were applied: coalescent regression, ridge regression, stepwise regression and random forest. Thirty-fold cross-validation was applied in each instance during the modelling process. Since stepwise regression is familiar to most clinicians, the approach was used for the primary analysis. The results from this process were applied using a $\mathrm{P}$ value of 0.01 to enter and 0.05 to stay in the model. Variables considered in the full model were: race, world region, type of $\mathrm{AF}$ at diagnosis, baseline use of NOAC or VKA, the composite of ADP or P2Y12 receptor inhibitors, aspirin, the composite of non-steroidal anti-inflammatory drugs (NSAIDs) or cyclooxygenase-2 (Cox-2) inhibitors, and/or AP treatments for $\mathrm{AF}$, gender, systolic and diastolic blood pressures, heart rate, age, current $\mathrm{CAD}$ or a history of stable angina, stent placement, myocardial infarction (MI), unstable angina, coronary artery bypass surgery (CABG), aortic disease, peripheral vascular disease, carotid disease, CKD, hypertension, stroke, TIA, SE, cirrhosis, current hypertension, a history of CHF or an ejection fraction less than 40, sleep apnoea and heavy alcohol consumption. Follow-up was censored at 1 year for those patients who were followed for a longer period. Comparison of the GARFIELD-AF risk model with existing scores $\left(\mathrm{CHA}_{2} \mathrm{DS}_{2}-\mathrm{VASc}\right.$ and HAS-BLED) was performed using two measures: display of C-index with $95 \%$ CI for a measure of discrimination and $\mathrm{P}$ values for the added value of each model to a 'super' model. In the latter case, one assumes the super model to include two factors: patient values multiplied by their respective model coefficients for the GARFIELD-AF risk model plus the score of interest. The difference in likelihood ratio test evaluates the added information of one model given the information from the other. If statistically significant, the model contains additional predictive information. If not significant, the first model alone contains most of the information in both. A third measure of the quality of the model is the calibration curves, which show how well the predicted values are calibrated to the actual rates observed. The eight factors with the largest Wald Chi-Squares $\left(\chi^{2}\right)$ were retained for the simplified model for all-cause mortality. Model coefficients were then regenerated on this reduced set of factors. For the other two models, few enough factors were retained with the stepwise process so that no further reduction in the number of variables was needed.

\section{External validation}

We evaluated the performance of the GARFIELD-AF risk model in an external AF population using data from ORBIT-AF, a prospective registry of 10132 patients with incident or prevalent AF (2010-2012). ${ }^{11}$ Each score was recreated according to the definitions given in the original GARFIELD-AF study, using baseline values from the first study visit in each registry. From the list of variables 
in the simplified model, only history of bleeding was unavailable in ORBIT-AF. History of gastrointestinal (GI) bleeding was substituted. The full list of definitions used to generate the scores in each dataset is provided in online supplementary table 1 . Online supplementary table 2 details the Wald $\chi^{2}, \mathrm{P}$ values and hazard ratio (HRs) for each component of the simplified GARFIELD-AF models for: all-cause mortality, ischaemic stroke/SE and major bleeding, including haemorrhagic stroke.

\section{RESULTS}

Table 1 provides the baseline characteristics for patients ( $\mathrm{n}=38935$ with $\mathrm{CHA}_{2} \mathrm{DS}_{2}$-VASc scores) and for patients stratified as either very low to low risk $\left(\mathrm{CHA}_{2} \mathrm{DS}_{2}\right.$-VASc 0 or 1 for men and 1 or 2 for women; $20.2 \%$ of patients). Higher risk was classified as $\mathrm{CHA}_{2} \mathrm{DS}_{2}-\mathrm{VASc}$ score $\geq 2$ for men and $\geq 3$ for women.

The 1 year Kaplan-Meier event rates by $\mathrm{CHA}_{2} \mathrm{DS}_{2}$-VASc score are given in figure 1 . Event rates were rare in the very low to low risk cohort: $1.3 \%$ all-cause mortality, $0.5 \%$ ischaemic stroke/SE and $0.5 \%$ with haemorrhagic stroke/major bleed. By comparison, the respective rates for each event in the cohort identified for the sensitivity analysis $\left(\mathrm{CHA}_{2} \mathrm{DS}_{2}\right.$-VASc of 0-2 for men, 1-3 for women; comprising $45.1 \%$ of patients in GARFIELD-AF) were: $4.9 \%, 1.5 \%$ and $1.2 \%$ (table 2); baseline characteristics for this cohort are in described online in supplementary table 3 .

\section{Performance of $\mathrm{CHA}_{2} \mathrm{DS}_{2}$-VASC and GARFIELD-AF risk models}

For all-cause mortality, the GARFIELD-AF risk model performed well in the overall population (C-index 0.77) (both treated and untreated with OAC) as well as in the lower risk groups (C-indices ranged from 0.69 to 0.72 ) (table 3 and the receiver operating characteristic (ROC) curves in figure 2). The discriminatory power of the model to identify patients at risk of ischaemic stroke/ SE had a C-index of 0.69 (in lower risk groups, C-indices ranged from 0.65 to 0.67 ) (table 3 ). The calibration curves (figure 3) showed that the estimates were closely aligned to actual rates for death and displayed adequate calibration for other two end points, in particular, in the lower risk groups.

The GARFIELD-AF risk model for any major bleeding (including haemorrhagic stroke) was based on the subset of 25677 patients who were on an OAC therapy for AF. This bleeding model had an overall C-index of 0.66 (95\% CI 0.62 to 0.69 ) (table 3 ).

Table 3 compares the performance of the $\mathrm{CHA}_{2} \mathrm{DS}_{2}-$ VASc (or HAS-BLED for bleeding) and GARFIELD-AF risk models in the overall population and in lower risk populations, respectively. The analyses showed that in the overall population, the discriminatory value of the GARFIELD-AF integrated risk model was superior to $\mathrm{CHA}_{2} \mathrm{DS}_{2}$-VASc for all-cause mortality, for stroke/SE and for major bleeding (overall population, table 3). GARFIELD-AF risk models contain information beyond that found in $\mathrm{CHA}_{2} \mathrm{DS}_{2}$-VASc or HAS-BLED in the overall population as well as in treated and untreated patients ( $\mathrm{p}<0.001$ for comparisons).

The GARFIELD-AF model also discriminated risk in the very low to low risk patients $\left(\mathrm{CHA}_{2} \mathrm{DS}_{2}\right.$-VASc 0 or 1 for men and 1 or 2 for women) and in those in the sensitivity analysis with a higher risk of stroke $\left(\mathrm{CHA}_{2} \mathrm{DS}_{2}-\right.$ VASc 0-2 for men and 1-3 for women) (table 3). Compared with $\mathrm{CHA}_{2} \mathrm{DS}_{2}$-VASc or HAS-BLED, the GARFIELD-AF models provided additional information for all endpoints except bleeding in the lower risk groups $(\mathrm{p}<0.001, \mathrm{p}<0.004$ and $\mathrm{p}<0.299)$. In contrast, $\mathrm{CHA}_{2} \mathrm{DS}_{2}-$ VASc offered poor discrimination (C-statistic in low-risk patients was 0.50 for mortality and 0.59 for ischaemic stroke/SE, table 3). $\mathrm{CHA}_{2} \mathrm{DS}_{2}$-VASc and HAS-BLED did not add information over the GARFIELD-AF risk score for any endpoint in the lower risk cohorts ( $\mathrm{P}$ values ranged from 0.087 to 1.00 ).

For patients with no risk factors other than gender, as identified by the $\mathrm{CHA}_{2} \mathrm{DS}_{2}$-VASc score ('very low' stroke risk), only 4 out of these 1579 patients experienced a stroke or SE and only 3 out of the 685 anticoagulated patients experienced a major bleed.

\section{Performance of the simplified GARFIELD-AF mortality risk predictor}

A simplified GARFIELD-AF risk model (potentially suitable for web applications) was developed for all-cause mortality. It included the following variables: age, pulse, systolic blood pressure, a history of vascular disease, history of bleeding, heart failure, renal disease and use of OAC. This model had a C-statistic of 0.77 (95\% CI 0.76 to 0.78 ) in the GARFIELD-AF population of 39898 patients.

\section{External validation of the web-based GARFIELD-AF risk models in the ORBIT-AF population}

The web-based GARFIELD-AF risk model was validated externally in an independent population from the US registry, ORBIT-AF (table 4). The calibration plots for the simplified GARFIELD-AF risk model in ORBIT-AF for 1-year mortality, ischaemic stroke/SE and major bleed (in treated patients) are shown in online supplementary figure 1 .

The predictive value of GARFIELD-AF risk models (full and simplified) for 1-year and 3-year all-cause mortality in patients enrolled in ORBIT-AF (overall and stratified with and without OAC treatment) is presented in table 4 . The C-statistic for 1-year mortality was 0.75 (95\% CI 0.73 to 0.77 ) in the simplified risk model and 0.75 (95\% CI 0.73 to 0.77 ) in full risk model (table 4). For any ischaemic stroke or SE over 1 year, the C-statistic was 0.69 (95\% CI 0.67 to $0.71)$ for the GARFIELD-AF population and 0.68 (95\% CI 0.62 to 0.74 ) in the 9743 patients from ORBIT-AF (online supplementary table 4 ). For major bleeding over 1 year, this was 0.66 (95\% CI 0.62 to 0.69 ) for the GARFIELD-AF population on OACs and 0.61 (95\% CI 0.58 to 0.64 ) for the respective population of 7442 patients in ORBIT-AF (online supplementary table 5 ). 
Table 1 Baseline characteristics ${ }^{*}$ for all patients in GARFIELD-AF and those with very low to low risk (defined by a CHA $\mathrm{DS}_{2}$ VASc score of 0 or 1 for men and 1 or 2 for women) compared with those with a higher risk ( $\mathrm{CHA}_{2} \mathrm{DS}_{2}-\mathrm{VASc}_{\mathrm{Score}}$ of $\geq 2$ for men and $\geq 3$ for women)

\begin{tabular}{|c|c|c|c|c|}
\hline & Very low to low risk $\mathrm{n}=7882$ & Higher risk $n=31053$ & Overall $n=38935$ & $P$ value \\
\hline Age (years) & $58.0(52-63)$ & $74.0(67-80)$ & $71.0(63-78)$ & $<0.001$ \\
\hline $\mathrm{SBP}(\mathrm{mm} \mathrm{Hg})$ & $130.0(118-140)$ & $134.0(120-146)$ & $131.0(120-145)$ & $<0.001$ \\
\hline $\mathrm{BMI}\left(\mathrm{kg} / \mathrm{m}^{2}\right)$ & $27.0(24-30)$ & $27.0(24-31)$ & $27.0(24-31)$ & 0.023 \\
\hline Pulse (bpm) & $83.0(70-105)$ & $84.0(70-105)$ & $84.0(70-105)$ & 0.326 \\
\hline Type of AF, n (\%) & & & & $<0.001$ \\
\hline Persistent & $1188(15.1)$ & $4736(15.3)$ & $5924(15.2)$ & \\
\hline Paroxysmal & $2686(34.1)$ & $8102(26.1)$ & $10788(27.7)$ & \\
\hline Unclassifiedł & $3396(43.1)$ & $13889(44.7)$ & $17285(44.4)$ & \\
\hline Gender, female, n (\%) & $2658(33.7)$ & $14649(47.2)$ & $17307(44.5)$ & $<0.001$ \\
\hline Race, n (\%) & & & & $<0.001$ \\
\hline Asian (not Chinese) & $2361(30.0)$ & $6183(19.9)$ & $8544(21.9)$ & \\
\hline Chinese & $523(6.6)$ & $1543(5.0)$ & $2066(5.3)$ & \\
\hline Mixed/other & $131(1.7)$ & $437(1.4)$ & $568(1.5)$ & \\
\hline Not declared/recorded & $142(1.8)$ & $724(2.3)$ & $866(2.2)$ & \\
\hline World region , n (\%) & & & & $<0.001$ \\
\hline Europe & $3869(49.1)$ & $18633(60.0)$ & $22502(57.8)$ & \\
\hline North America & $192(2.4)$ & $919(3.0)$ & $1111(2.9)$ & \\
\hline Latin America & $606(7.7)$ & $2661(8.6)$ & $3267(8.4)$ & \\
\hline Asia & $2982(37.8)$ & 7869 (25.3) & 10851 (27.9) & \\
\hline Rest of world§ & $233(3.0)$ & $971(3.1)$ & $1204(3.1)$ & \\
\hline History of carotid artery disease, $\mathrm{n}(\%)$ & $57(0.7)$ & $1127(3.7)$ & $1184(3.1)$ & $<0.001$ \\
\hline History of stent use, $\mathrm{n}(\%)$ & $139(1.8)$ & $2425(7.8)$ & $2564(6.6)$ & $<0.001$ \\
\hline History of CABG, $n(\%)$ & $33(0.4)$ & $1127(3.7)$ & $1160(3.0)$ & $<0.001$ \\
\hline History of stroke, n (\%) & $0(0.0)$ & $3030(9.8)$ & $3030(7.8)$ & $<0.001$ \\
\hline History of alcohol abuse, $\mathrm{n}(\%)$ & $289(4.2)$ & $501(1.9)$ & $790(2.4)$ & $<0.001$ \\
\hline History of bleeding, $\mathrm{n}(\%)$ & $108(1.4)$ & $916(3.0)$ & $1024(2.6)$ & $<0.001$ \\
\hline Kidney disease, n (\%) & $225(3.3)$ & $3813(14.2)$ & $4038(12.0)$ & $<0.001$ \\
\hline NSAID/Cox-2 inhibitor, n (\%) & $2052(26.0)$ & $9138(29.4)$ & $11190(28.7)$ & $<0.001$ \\
\hline \multicolumn{5}{|l|}{ Antithrombotic at diagnosis of AF, $\mathrm{n}(\%)$} \\
\hline Antiplatelet & $2588(32.8)$ & $11496(37.0)$ & $14084(36.2)$ & $<0.001$ \\
\hline NOAC & $1631(20.7)$ & $7173(23.1)$ & $8804(22.6)$ & $<0.001$ \\
\hline VKA & $2531(32.1)$ & $13960(45.0)$ & $16491(42.4)$ & $<0.001$ \\
\hline
\end{tabular}

Note: The baseline analyses for the low-to-intermediate group provided midway results, between the very low to low risk and high risk groups, which are detailed in full in the appendix.

$\mathrm{P}$ value comparison of very low to low risk versus higher risk patients.

*Median with 25th and 75th percentiles for continuous variables, $\mathrm{N}(\%)$ for categorical.

tVery low to low risk is defined by a $\mathrm{CHA}_{2} \mathrm{DS}_{2}$-VASc score of 0 or 1 for men and 1 or 2 for women.

$\ddagger$ The term unclassified is used when the type of AF could not be accurately determined in the short interval between diagnosis of $A F$ and enrolment into the study. §Rest of world: Australia, Egypt and South Africa.

AF, atrial fibrillation; BMI, body mass index; CABG, coronary artery bypass graft; Cox-2, cyclooxygenase-2; DBP, diastolic blood pressure; GARFIELD-AF, Global Anticoagulant Registry in the FIELD-Atrial Fibrillation; NSAID, non-steroidal anti-inflammatory drug; NOAC, new (or non-vitamin K) oral anticoagulant; SBP, systolic blood pressure; VKA, vitamin K antagonists. 


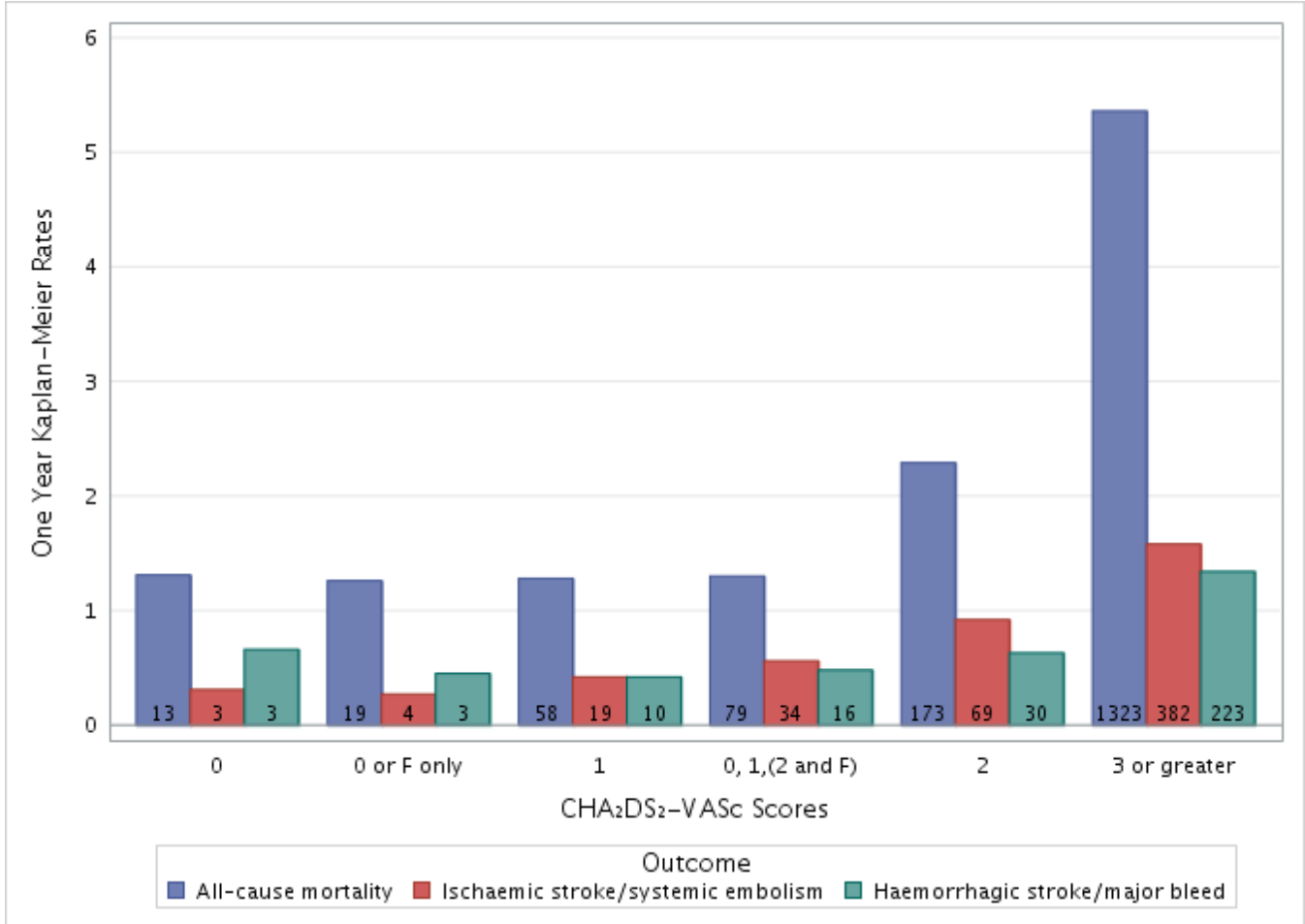

Figure 1 One-year Kaplan-Meier event rates by $\mathrm{CHA}_{2} \mathrm{DS}_{2}$-VASc score for all-cause mortality, ischaemic stroke/systemic embolism and haemorrhagic stroke/major bleed. F, female.

In analyses of all ORBIT-AF patients and those stratified with and without OAC treatment, the performance of the GARFIED-AF risk model was comparable with $\mathrm{CHA}_{2} \mathrm{DS}_{2}-$ VASc for the prediction of ischaemic stroke/SE at 1-year and 3-year follow-up (online supplementary table 4) and comparable with the ATRIA score in predicting major bleed in patients on OAC treatment (online supplementary table 5).

\section{DISCUSSION}

Large-scale trials of NOACs ${ }^{21-28}$ have raised awareness of the potential benefits of anticoagulation for patients with $\mathrm{AF}$ and at least one risk factor for stroke/SE. Observational studies including GARFIELD-AF ${ }^{7}$ have demonstrated that,

Table 2 One-year Kaplan-Meier event rates in patients with a $\mathrm{CHA}_{2} \mathrm{DS}_{2}-\mathrm{VASc}$ 0-2 (men) or 1-3 (women) compared with remaining cohort ( $\mathrm{CHA}_{2} \mathrm{DS}_{2}-\mathrm{VASc}$ score of $\geq 3$ for men and $\geq 4$ for women)

\begin{tabular}{lcl}
\hline Event & $\begin{array}{l}\text { CHA }_{2} \text { DS }_{2} \text {-VASc 0-2 } \\
\text { (men) or 1-3 (women) }\end{array}$ & $\begin{array}{l}\text { Remaining } \\
\text { cohort }\end{array}$ \\
\hline $\begin{array}{l}\text { All-cause mortality, } \\
\mathrm{n}(\%)\end{array}$ & $341(2.0)$ & $1226(5.9)$ \\
$\begin{array}{l}\text { Ischaemic } \\
\text { stroke/systemic } \\
\text { embolism, n (\%) }\end{array}$ & $128(0.8)$ & $345(1.7)$ \\
$\begin{array}{l}\text { Haemorrhagic } \\
\text { stroke/major bleed, } \\
\mathrm{n}(\%)\end{array}$ & $67(0.7)$ & $199(1.4)$ \\
\hline
\end{tabular}

over time, patients are increasingly likely to be anticoagulated (57\% in 2010-2011, rising to $71 \%$ in $2014-2015$ in GARFIELD-AF among patients whom clinicians believe have a risk of stroke). However, despite guideline recommendations, ${ }^{1-3}$ observational studies also demonstrate overuse of OACs in low-risk patients and underuse in high-risk patients in comparison with predicted use based on the $\mathrm{CHA}_{2} \mathrm{DS}_{2}$-VASc score and guideline recommendations. ${ }^{25-27}$ The GARFIELD-AF study found that patients with a $\mathrm{CHA}_{2} \mathrm{DS}_{2}$-VASc score of 0 in men, 1 in women were at very low risks of stroke (4 out of 1579). The implications are that risks may not outweigh benefits in such patients. It is also likely that underuse of OAC in patients with high risk of stroke is because of the perceived risk of bleeding. The findings from GARFIELD-AF indicate that factors beyond those included in the composite of variables for stroke risk scores appear to influence prescribing decisions on anticoagulation. Current risk scores are complex (and do not reflect all risk factors, eg, renal insufficiency) and do not allow simultaneous prediction of ischaemic stroke/SE, bleeding risk and mortality.

The rationale behind this report is to provide clinicians with a more accurate and integrated method for stratifying patients according to their risks of death, stroke and major bleeding, and thereby facilitate decisions on prescribing or withholding anticoagulation and hence encourage greater guideline adherence.

By including all-cause mortality as a new element of the risk model, we hope that this will also encourage a more holistic approach to the management of patients with $\mathrm{AF}$ as well as aiding decisions on anticoagulation. As the 
Table 3 Comparison of the performance of the new GARFIELD-AF risk model with $\mathrm{CHA}_{2} \mathrm{DS}_{2}-\mathrm{VASc}$ (death, stroke or systemic embolism) or HAS-BLED* for major bleeding in all patients overall and by treated and untreated with anticoagulation and also for patients with lower stroke risk.

\begin{tabular}{|c|c|c|c|c|}
\hline \multirow[b]{2}{*}{ Events } & \multicolumn{2}{|l|}{ C-index } & \multicolumn{2}{|c|}{$\begin{array}{l}\text { P value of test for one risk model over } \\
\text { the other }\end{array}$} \\
\hline & $\begin{array}{l}\text { GARFIELD-AF risk } \\
\text { model }\end{array}$ & $\begin{array}{l}\text { CHA }_{2} \text { DS }_{2}-\text { VASc } \\
\text { (HAS-BLED for }^{\text {bleeding)* }}\end{array}$ & $\begin{array}{l}\text { GARFIELD-AF risk } \\
\text { model }\end{array}$ & $\begin{array}{l}\mathrm{CHA}_{2} \mathrm{DS}_{2}-\mathrm{VASc} \\
\text { (HAS-BLED for } \\
\text { bleeding) }^{*}\end{array}$ \\
\hline \multicolumn{5}{|l|}{ All patients } \\
\hline All-cause mortality & $0.77(0.76-0.78)$ & $0.66(0.64-0.67)$ & $<0.001$ & 0.165 \\
\hline Anticoagulant treated & $0.75(0.73-0.77)$ & $0.65(0.63-0.66)$ & $<0.001$ & 0.186 \\
\hline Anticoagulant untreated & $0.78(0.77-0.80)$ & $0.68(0.66-0.70)$ & $<0.001$ & 0.507 \\
\hline Ischaemic stroke/systemic embolism & $0.69(0.67-0.71)$ & $0.64(0.61-0.66)$ & $<0.001$ & 0.006 \\
\hline Anticoagulant treated & $0.67(0.64-0.71)$ & $0.64(0.60-0.67)$ & $<0.001$ & 0.020 \\
\hline Anticoagulant untreated & $0.69(0.65-0.72)$ & $0.65(0.61-0.68)$ & $<0.001$ & 0.047 \\
\hline Major bleed (anticoagulant treated) & $0.66(0.62-0.69)$ & $0.64(0.61-0.68)^{*}$ & $<0.001$ & $0.001^{*}$ \\
\hline \multicolumn{5}{|c|}{$\begin{array}{l}\text { Very low to low risk patients } \\
\text { CHA,DS,-VASc score of } 0 \text { or } 1 \text { (men) and } 1 \text { or } 2 \text { (women); HAS-BLED } 0 \text { for bleeding }\end{array}$} \\
\hline All-cause mortality & $0.69(0.64-0.75)$ & $0.50(0.45-0.55)$ & $<0.001$ & 0.383 \\
\hline Ischaemic stroke/systemic embolism & $0.65(0.56-0.73)$ & $0.59(0.50-0.67)$ & 0.004 & 0.108 \\
\hline Major bleed (anticoagulant treated) & $0.60(0.47-0.73)$ & $0.55(0.53-0.56)^{*}$ & 0.299 & $0.403^{*}$ \\
\hline \multicolumn{5}{|c|}{$\begin{array}{l}\text { Low to intermediate or higher risk patients (sensitivity analysis) } \\
\mathrm{CHA}_{2} \mathrm{DS}_{2} \text {-VASc score } 0,1 \text { or } 2 \text { (men) and } 1,2 \text { or } 3 \text { (women); HAS-BLED score } 0 \text { or } 1 \text { for bleeding }\end{array}$} \\
\hline All-cause mortality & $0.72(0.70-0.75)$ & $0.56(0.54-0.59)$ & $<0.001$ & 0.377 \\
\hline Ischaemic stroke/systemic embolism & $0.67(0.63-0.72)$ & $0.58(0.54-0.62)$ & $<0.001$ & 0.087 \\
\hline Major bleed (anticoagulant treated) & $0.64(0.58-0.71)$ & $0.62(0.58-0.65)^{\star}$ & 0.001 & $1.000^{\star}$ \\
\hline
\end{tabular}

GARFIELD-AF, Global Anticoagulant Registry in the FIELD-Atrial Fibrillation.

new model is more accurate than HAS-BLED in identifying those at higher bleeding risk, this affords clinicians with a more reliable basis for taking steps to more closely monitor patients and modify any potentially reversible bleeding risks.

Initiatives such as the GARFIELD-AF model may enable guideline groups in the future to recommend anticoagulation treatment based on thresholds (according to predicted event rates) for stroke, major bleeding and all-cause mortality, rather than using conventional risk scores.

The GARFIELD-AF score has the potential to be incorporated into routine electronic record systems and to automatically calculate mortality, stroke and bleeding risks based on routinely collected data. This obviates the current need for separate stroke and bleeding risk calculations for each patient and allows the clinician to evaluate all these risks when deciding on whether to recommend anticoagulation. As healthcare systems increasingly adopt electronic health records for the management of patients, this will allow users to base treatment decisions on more precise measures of risk, including risks of mortality, stroke and bleeding using a single risk scoring system.

For patients with AF and clearly elevated stroke risk, guidelines recommend anticoagulation irrespective of a $\mathrm{CHA}_{2} \mathrm{DS}_{2}$-VASc score of 2, 3 or more (provided the risks of bleeding are not excessive). However, differentiation of those with low stroke risk is more challenging. Few studies include sufficiently high numbers of patients to accurately assess lower risk patients. The populations used to derive $\mathrm{CHA}_{2} \mathrm{DS}_{2}$-VASc, for example, contained very few very low risk patients (103 patients had a $\mathrm{CHA}_{2} \mathrm{DS}_{2}-$ VASc score of 0 , and 162 patients a score of 1). ${ }^{4}$ Although $\mathrm{CHA}_{2} \mathrm{DS}_{2}$-VASc was subsequently reassessed using data from Danish ${ }^{29}$ and Swedish national registries, ${ }^{30}$ the value of $\mathrm{CHA}_{2} \mathrm{DS}_{2}$-VASc in defining patients with a truly low risk of stroke is uncertain. ${ }^{31}$

This study demonstrates that a novel computer-generated risk model, derived from GARFIELDAF, is superior to $\mathrm{CHA}_{2} \mathrm{DS}_{2}$-VASc in predicting ischaemic stroke/SE overall, and in very low to low risk patients with a $\mathrm{CHA}_{2} \mathrm{DS}_{2}$-VASc score of 0 or 1 (for men) or 1 or 2 (for women) who may not benefit from anticoagulation (as defined by the 2016 ESC Guidelines ${ }^{6}$ ).

Notably, the contemporary data from GARFIELD-AF showed that patients with AF being considered for anticoagulation have lower risks of ischaemic stroke/SE than seen in older reports. In GARFIELD-AF, the rate of ischaemic stroke/SE per 100-person years $(1.6 \%)$ is less than half the previously reported rate of $3.9 \%$ (95\% CI $1.7 \%$ to $7.6 \%$ unadjusted for aspirin) reported by Lip et al in $2010^{17}$ for patients with a CHA DS $_{2}$-VASc score of 3.0 (ie, 

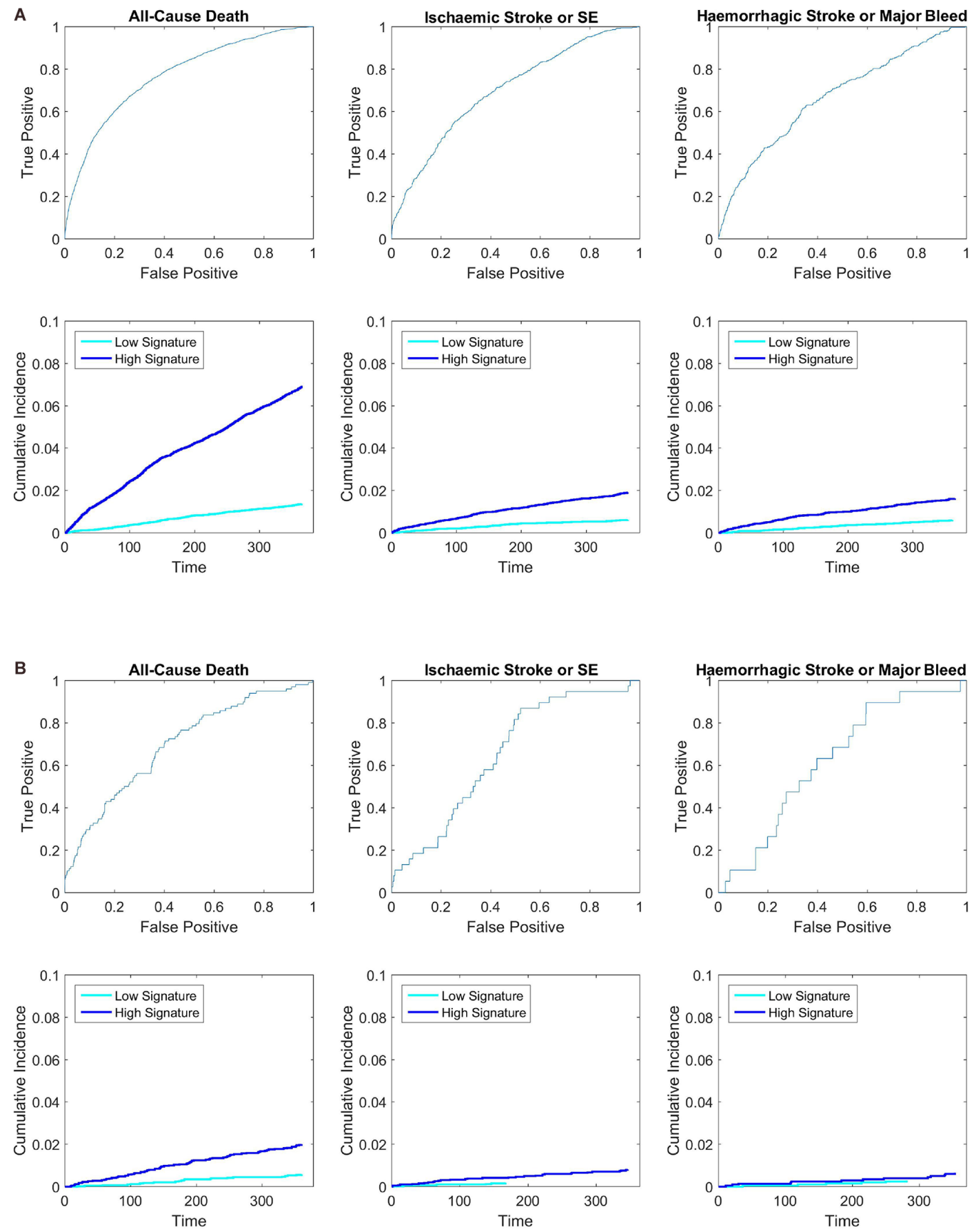

Figure 2 Receiver operating characteristic curves and 1 year Kaplan-Meier curves, dividing the data at median predicted risk, in: (A) all GARFIELD-AF patients and (B) very low to low risk patients ( $\mathrm{CHA}_{2} \mathrm{DS}_{2}-\mathrm{VASc}$ of 0 or 1 for men and 1 or 2 for women). The sample sizes for the three groups in the overall population are 39898,39898 and 25677 , respectively. Eighty-five per cent of patients were still in the cohort by the end of the 1-year period. The median 1 year risk for the three overall KM figures are $2.7 \%$ death, $0.95 \%$ ischaemic stroke/SE, $0.92 \%$ haemorrhagic stroke or major bleed. The median 1 year risk for the three lower risk KM figures are: $0.92 \%$ death, $0.43 \%$ ischaemic stroke/SE, $0.35 \%$ haemorrhagic stroke or major bleed. SE, systemic embolism.

the mean score in the GARFIELD-AF cohort). This probably reflects the impact of anticoagulation and the higher proportion of patients who are considered for anticoagulants, compared with data from populations collected before 2010 .

The GARFIELD-AF model performed significantly better than $\mathrm{CHA}_{2} \mathrm{DS}_{2}$-VASc for all-cause mortality. This is unsurprising since the GARFIELD-AF model assesses multiple variables at the same time, while the
$\mathrm{CHA}_{2} \mathrm{DS}_{2}$-VASc score was designed only to assess ischaemic stroke.

As well as the full GARFIELD-AF model for all-cause mortality, we derived a simplified GARFIELD-AF risk tool for all-cause mortality (plus the original risk models for stroke/SE or bleeding) for easy use in diverse healthcare systems via the web or with a portable electronic device. The simplified tool performed as well among patients treated with OACs as among 

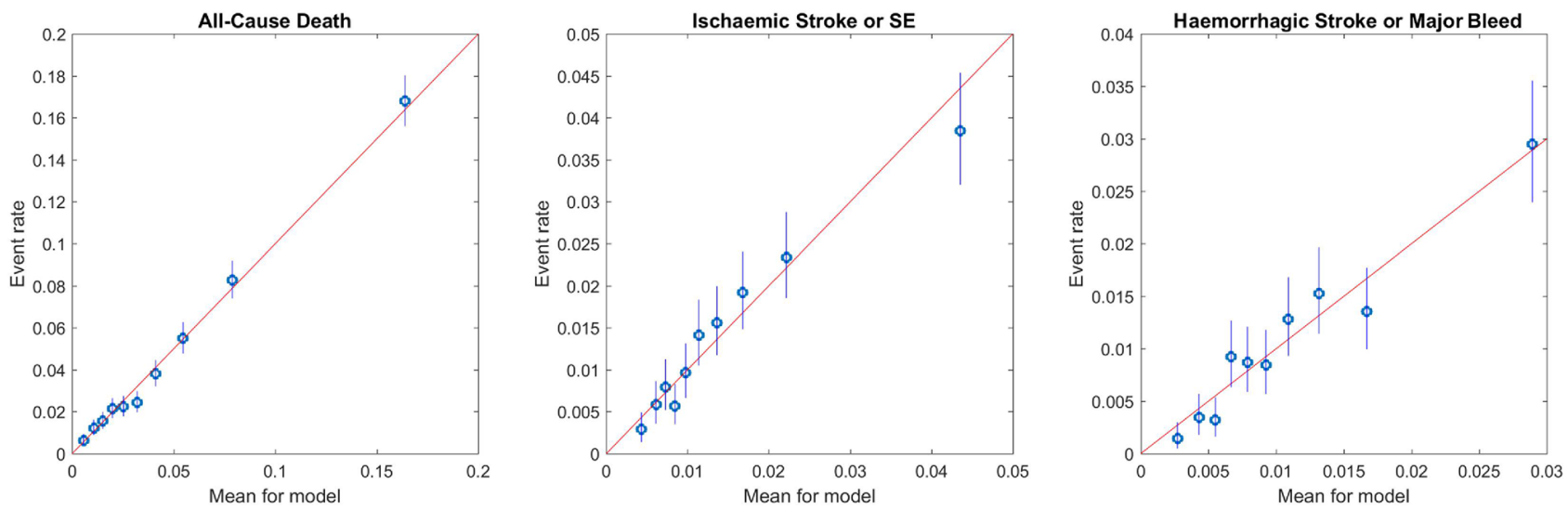

Figure 3 Calibration of GARFIELD-AF risk model for each end point in the GARFIELD-AF population. GARFIELD-AF, Global Anticoagulant Registry in the FIELD-Atrial Fibrillation; SE, systemic embolism.

non-anticoagulated patients and was validated using an independent contemporary registry from the USA, ORBIT-AF.

A potential limitation of our analyses is that the GARFIELD risk tool was developed on all patients. Patients who are not prescribed anticoagulation treatment do not have the same characteristics and baseline features as those who are anticoagulated. For these reasons, the GARFIELD-AF risk tool was developed on all patients and included oral anticoagulants as an adjustment factor to account for the change in risk after anticoagulation is used.

Furthermore, we were not able to conduct an external validation of GARFIELD-AF risk tool in the low risk patients because ORBIT-AF did not recruit sufficient low-risk patients for this analysis. We anticipate that by making this risk score available, others will be able to test the performance of the GARFIELD-AF risk tool in large national datasets with the full spectrum of risk.

Table 4 Evaluation of performance (C-statistic (95\% Cls)) of the GARFIELD-AF risk models (full and simplified) in predicting all-cause mortality in patients enrolled in ORBIT$\mathrm{AF}$ (overall and stratified with and without OAC treatment)

\begin{tabular}{cll}
\hline & $\begin{array}{l}\text { GARFIELD-AF } \\
\text { Full risk model }\end{array}$ & $\begin{array}{l}\text { GARFIELD-AF } \\
\text { Simplified risk } \\
\text { model }\end{array}$ \\
\hline $\begin{array}{c}\text { 1-year mortality } \\
\text { Anticoagulant } \\
\text { treated }\end{array}$ & $0.75(0.73$ to 0.77$)$ & $0.75(0.73$ to 0.77$)$ \\
$\begin{array}{l}\text { Anticoagulant } \\
\text { untreated }\end{array}$ & $0.74(0.72$ to 0.77$)$ & $0.74(0.71$ to 0.76$)$ \\
$\begin{array}{l}\text { 3-year mortality } \\
\text { Anticoagulant } \\
\text { treated }\end{array}$ & $0.74(0.73$ to 0.80$)$ & $0.76(0.72$ to 0.79$)$ \\
$\begin{array}{l}\text { Anticoagulant } \\
\text { untreated }\end{array}$ & $0.76)$ & $0.74(0.73$ to 0.75$)$ \\
\hline
\end{tabular}

GARFIELD-AF, Global Anticoagulant Registry in the FIELD-Atrial

Fibrillation; OAC, oral anticoagulant.
Overall, we recognise that the calibration of the new scores in the ORBIT population was not as good as in the original cohort because ORBIT-AF included patients with prevalent $\mathrm{AF}$ whereas AF-GARFIELD included new onset $\mathrm{AF}$, and hence risk characteristics and outcomes differed.

We recognised there are other differences in the risk characteristics and outcomes between the GARFIELD-AF and ORBIT-AF populations, including the higher use of anticoagulation in the ORBIT-AF population from the USA. Although broad global representation is a strength of the GARFIELD-AF score, it is recognised that there are wide variations in outcomes and treatment practices across countries with different healthcare systems. Calibration to the regional averages rather than overall averages provided some refinement to the estimates of risk. We would encourage others to test the performance of GARFIELD-AF score in various large national or regional datasets.

Despite a stringent model derivation, there were a few surprising findings in the factors included in the models. For example, 'history of bleeding' (which may be surrogate for suboptimal OAC therapy) was not independently predictive of future bleed but appeared to be an independent predictor for ischaemic stroke (see online supplementary table 2). Similarly, vascular disease was among the variables in the bleeding risk model. This may due to confounding with dual or triple antithrombotic therapy in the registry, but even with AP in the model, the term 'vascular disease' remained significant $(\mathrm{p}=0.007)$.

Finally, the GARFIELD-AF model reflects the limitations of data collected in routine practice. For example, it should be noted that the presence and severity of renal disease, as a factor in the GARFIELD-AF score, was determined by clinicians and the risk calculation was not supplemented by the collection of laboratory values for kidney function. Although it is recognised that additional variables, including certain biomarkers, may have value for improved prediction of the risk of outcome events, ${ }^{32}$ these are not routinely collected in clinical practice. In order to validate the GARFIELD-AF risk tool in different geographic populations and various datasets, we would 
encourage further evaluation of its performance in diverse large national datasets.

\section{Conclusions}

The GARFIELD-AF risk model predicted all-cause mortality, stroke/SE and major bleeding including haemorrhagic stroke with an accuracy that was superior to $\mathrm{CHA}_{2} \mathrm{DS}_{2}$-VASc (and also to HAS-BLED for bleeding), in the overall population and in patients with a lower risk of stroke. The simplified GARFIELD-AF risk tool, with potential web applications, performed as well among patients treated with OACs as among non-anticoagulated patients and was validated using an independent contemporary registry. Use of an integrated risk predictor, such as the GARFIELD-AF risk tool, has the potential to assist clinicians in applying evidence-based guidelines to anticoagulation decisions for patients with $\mathrm{AF}$ and possible stroke risk.

\section{Author affiliations}

${ }^{1}$ Edinburgh Centre for Cardiovascular Science, University of Edinburgh, Edinburgh, UK

${ }^{2}$ Department of Statistical Science, Duke University, Durham, North Carolina, USA

${ }^{3}$ Department of Statistical Research Science, Duke Clinical Research Institute,

Durham, North Carolina, USA

${ }^{4}$ Department of Cardiology, University of BesanÃßon, BesanÃßon, France

${ }^{5}$ Department of Clinical Research, Thrombosis Research Institute (TRI), London, UK

${ }^{6}$ Department of Clinical Cardiology, St George's University London, London, UK

${ }^{7}$ Department of Cardio-respiratory Primary Care, Warwick Medical School,

University of Warwick, Coventry, UK

${ }^{8}$ Department of Medicine, Brigham and Women's Hospital and Harvard Medical

School, Boston, Massachusetts, USA

${ }^{9}$ Department of Medicine, Tokai University, Kanagawa, Japan

${ }^{10}$ Department of Medicine, Formerly Technical University Of Munich, Munich, Germany

${ }^{11}$ Department of Neurology, University of Heidelberg, Heidelberg, Germany

${ }^{12}$ Department of Cardiology, Hacettepe University, Ankara, Turkey

${ }^{13}$ Department of Statistics and Quantitative Methods, University of Milano-Bicocca, Milan, Italy

${ }^{14}$ Department of Cardiovascular \& Coagulation, Bayer AG, Berlin, Germany

${ }^{15}$ Department of Medicine, McMaster University, Hamilton, Canada

${ }^{16}$ Department of Cardiology, University Hospital, Nijmegen, The Netherlands

${ }^{17}$ Department of Cardiology, Onze Lieve Vrouwe Gasthuis, Amsterdam, The

Netherlands

${ }^{18}$ Department of Surgery, University College London, London, UK

Acknowledgements We would like to thank the physicians, nurses and patients involved in the GARFIELD-AF registry. Editorial support was provided by Rae Hobbs (TRI, London, UK) and SAS programming support by Jagan Allu (TRI, London, UK).

Contributors KAAF, J-PB, AJC, DAF, SZG, SG, SH, WH, GK, FM, LGM, AO, AGGT, FWAV and AKK contributed to the study design. KAAF, AJC, J-PB, DAF, SZG, SG, A0 and JPP contributed to data acquisition. KSP and JEL analysed the data. All authors contributed to data interpretation. KAAF drafted the report. All authors critically reviewed the report and approved the final manuscript.

Funding This work was supported by an unrestricted research grant from Bayer AG, Berlin, Germany, to TRI, London, UK, which sponsors the GARFIELD-AF registry.

Competing interests KAAF reports grants and personal fees from Bayer, and Johnson and Johnson, personal fees from Lilly, grants and personal fees from AstraZeneca and personal fees from Sanofi/Regeneron outside the submitted work. JEL and KSP have provided statistical support and thought leadership for the Thrombosis Research Institute, during the conduct of the study, and KSP has received personal fees from Bayer outside the submitted work. J-PB reports personal fees from Aspen outside the submitted work. AJC is an advisor to Bayer, Boehringer Ingelheim, Pfizer/BMS and Daiichi Sankyo. DAF reports personal fees from Bayer outside the submitted work. SZG reports grants from Bi02 Medical,
Boehringer-Ingelheim, Bristol Meyers Squibb, BTG EKOS, Daiichi Sankyo, National Heart Lung and Blood Institute of the National Institutes of Health, Janssen and Thrombosis Research Group and personal fees from Bayer, Boehringer-Ingelheim, Bristol Meyers Squibb, Daiichi Sankyo, Janssen and Portola outside the submitted work. SG reports personal fees from Bayer, grants from Sanofi, grants from Pfizer, personal fees from Daiichi-Sankyo, personal fees from AstraZeneca during the conduct of the study and grants from Bayer outside the submitted work. SH reports personal fees from Aspen, Bayer AG, BMS, Daiichi-Sankyo, Pfizer and Sanofi outside the submitted work. WH reports personal fees from Bayer during the conduct of the study. GK reports grants from Bayer during the conduct of the study. LGM reports grants and personal fees from Bayer AG during the conduct of the study, and grants from Boehringer Ingelheim, grants and personal fees from Pfizer and personal fees from Daiichi Sankyo outside the submitted work. FM reports grants and other from Bayer $A G$ during the conduct of the study, and other from Bayer AG outside the submitted work. FM is an employee of Bayer AG. JP has nothing to disclose. AGGT reports consultant fees from Bayer AG during the conduct of the study. FWAV reports personal fees from Boehringer-Ingelheim, Bayer AG, BMS/Pfizer and Daiichi-Sankyo during the conduct of the study and personal fees from AstraZeneca outside the submitted work. AKK reports grants and personal fees from Bayer AG, Boehringer-Ingelheim Pharma, Daiichi Sankyo Europe, Sanofi SA and Janssen Pharma outside the submitted work.

Patient consent Obtained.

Ethics approval Independent ethics committee and hospital-based institutional review board approvals were obtained, as necessary, for the registry protocol.

Provenance and peer review Not commissioned; externally peer reviewed.

Data sharing statement No additional data available.

Open Access This is an Open Access article distributed in accordance with the Creative Commons Attribution Non Commercial (CC BY-NC 4.0) license, which permits others to distribute, remix, adapt, build upon this work non-commercially, and license their derivative works on different terms, provided the original work is properly cited and the use is non-commercial. See: http://creativecommons.org/ licenses/by-nc/4.0/

(C) Article author(s) (or their employer(s) unless otherwise stated in the text of the article) 2017. All rights reserved. No commercial use is permitted unless otherwise expressly granted.

\section{REFERENCES}

1. Camm AJ, Lip GY, De Caterina R, et al. 2012 focused update of the ESC Guidelines for the management of atrial fibrillation: an update of the 2010 ESC Guidelines for the management of atrial fibrillation. Developed with the special contribution of the European Heart Rhythm Association. Eur Heart J 2012;33:2719-47.

2. You JJ, Singer DE, Howard PA, et al. Antithrombotic therapy for atrial fibrillation: antithrombotic therapy and prevention of thrombosis, 9th ed: American College of Chest Physicians Evidence-Based Clinical Practice Guidelines. Chest 2012;141:e531S-75.

3. January CT, Wann LS, Alpert JS, et al. AHA/ACC/HRS guideline for the management of patients with atrial fibrillation: a report of the American College of Cardiology/American Heart Association Task Force on practice guidelines and the Heart Rhythm Society. Circulation 2014;130:e199-e267.

4. Lip GYH, Nieuwlaat R, Pisters R, et al. Refining clinical risk stratification for predicting stroke and thromboembolism in atrial fibrillation using a novel risk factor-based approach: the euro heart survey on atrial fibrillation. Chest 2010;137:263-72.

5. Gage BF, Waterman AD, Shannon W, et al. Validation of clinical classification schemes for predicting stroke: results from the National Registry of Atrial Fibrillation. JAMA 2001;285:2864-70.

6. Kirchhof P, Benussi S, Kotecha D, et al. 2016 ESC Guidelines for the management of atrial fibrillation developed in collaboration with EACTS. Eur Heart J 2016;37:2893-962.

7. Camm AJ, Accetta G, Ambrosio G, et al. Evolving antithrombotic treatment patterns for patients with newly diagnosed atrial fibrillation. Heart 2017;103:307-14.

8. Kakkar AK, Mueller I, Bassand J-P, et al. International longitudinal registry of patients with atrial fibrillation at risk of stroke: Global Anticoagulant Registry in the FIELD (GARFIELD). Am Heart $J$ 2012;163:13-19.

9. Granger CB, et al. Predictors of hospital mortality in the global registry of acute coronary events. Arch Intern Med 2003;163:2345-53. 
10. Liu L, Forman S, Barton B. Fitting Cox model using PROC PHREG and beyond in SAS. $2009 \mathrm{http}: / /$ support.sas.com/resources/papers/ proceedings09/236-2009.pdf

11. Piccini JP, Fraulo ES, Ansell JE, et al. Outcomes registry for better informed treatment of atrial fibrillation: Rationale and design of ORBIT-AF. Am Heart J 2011;162:606-12.

12. Golwala H, Jackson LR, Simon DN, et a/Racial/ethnic differences in atrial fibrillation symptoms, treatment patterns, and outcomes: Insights from Outcomes Registry for Better Informed Treatment for Atrial Fibrillation Registry. Am Heart J 2016;174:29-36.

13. Gundlund A, Fosbøl EL, Kim S, et al. Family history of atrial fibrillation is associated with earlier-onset and more symptomatic atrial fibrillation: Results from the Outcomes Registry for Better Informed Treatment of Atrial Fibrillation (ORBIT-AF) registry. Am Heart $J$ 2016:175:28-35.

14. O'Brien EC, Kim S, Thomas L, et al. Clinical characteristics, oral anticoagulation patterns, and outcomes of medicaid patients with atrial fibrillation: insights from the Outcomes registry for better informed treatment of atrial fibrillation (ORBIT-AF I) registry. J Am Heart Assoc 2016;5:e002721.

15. Henao R, Lucas JE. Efficient model-based clustering with coalescents: Application to multiple outcomes using medical records data. 2016 http://arxiv.org/abs/1608.03191.

16. Motwani M, Dey D, Berman DS, et al. Machine learning for prediction of all-cause mortality in patients with suspected coronary artery disease: a 5-year multicentre prospective registry analysis. Eur Heart $J$ 2017;38:500-7.

17. Marinigh R, Lip GY, Fiotti N, et al. Age as a risk factor for stroke in atrial fibrillation patients: implications for thromboprophylaxis. J Am Coll Cardiol 2010;56:827-37.

18. Pisters R, Lane DA, Nieuwlaat R, et al. A novel user-friendly score (HAS-BLED) to assess 1-year risk of major bleeding in patients with atrial fibrillation: the Euro Heart Survey. Chest 2010;138:1093-100.

19. Fox KAA, Gersh BJ, Traore S, et al. Evolving quality standards for large-scale registries - The GARFIELD-AF experience. Eur Heart $J$ Qual Care Clin Outcomes 2017;3:144-22.

20. National Kidney Foundation. K/DOQI clinical practice guidelines for chronic kidney disease: evaluation, classification, and stratification. Am J Kidney Dis 2002;39(2 Suppl 1):S1-266.
21. Piccini JP, Hellkamp AS, Lokhnygina Y, et al. Relationship between time in therapeutic range and comparative treatment effect of rivaroxaban and warfarin: results from the ROCKET AF trial. $J$ Am Heart Assoc 2014;3:e000521.

22. Piccini JP, Garg J, Patel MR, et al. Management of major bleeding events in patients treated with rivaroxaban vs. warfarin: results from the ROCKET AF trial. Eur Heart J 2014:35:1873-80.

23. Coppens M, Synhorst D, Eikelboom JW, et al. Efficacy and safety of apixaban compared with aspirin in patients who previously tried but failed treatment with vitamin $\mathrm{K}$ antagonists: results from the AVERROES trial. Eur Heart J 2014;35:1856-63.

24. Connolly SJ, Ezekowitz MD, Yusuf S, et al. Dabigatran versus warfarin in patients with atrial fibrillation. $N$ Engl $J$ Med Overseas Ed 2009;361:1139-51

25. Giugliano RP, Ruff CT, Braunwald E, et al. Edoxaban versus warfarin in patients with atrial fibrillation. N Engl J Med Overseas Ed 2013;369:2093-104.

26. O'Donoghue ML, Ruff CT, Giugliano RP, et al. Edoxaban vs. warfarin in vitamin $\mathrm{K}$ antagonist experienced and naive patients with atrial fibrillationt. Eur Heart J 2015;36:1470-7.

27. Granger CB, Alexander JH, McMurray JJV, et al. Apixaban versus warfarin in patients with atrial fibrillation. N Engl J Med Overseas Ed 2011;365:981-92.

28. Patel MR, Mahaffey KW, Garg J, et al. Rivaroxaban versus warfarin in nonvalvular atrial fibrillation. $N$ Engl J Med Overseas Ed 2011;365:883-91.

29. Olesen JB, Lip GYH, Hansen ML, et al. Validation of risk stratification schemes for predicting stroke and thromboembolism in patients with atrial fibrillation: nationwide cohort study. BMJ 2011;342:d124.

30. Friberg L, Rosenqvist M, Lip GYH. Evaluation of risk stratification schemes for ischaemic stroke and bleeding in 182678 patients with atrial fibrillation: the Swedish Atrial Fibrillation cohort study. Eur Heart $J$ 2012;33:1500-10.

31. Friberg $L$, Skeppholm M, Terént $A$. Benefit of anticoagulation unlikely in patients with atrial fibrillation and a CHA2DS2-VASc score of 1.J Am Coll Cardiol 2015;65:225-32.

32. Ruff CT, Giugliano RP, Braunwald E, et al. Cardiovascular biomarker score and clinical outcomes in patients with atrial fibrillation: a subanalysis of the ENGAGE AF-TIMI 48 randomized clinical trial. JAMA cardiology 2016;1:999-1006. 